\title{
Development of Regression Models to Measure Energy and Inflation Time of a Fabricated Tyre Pressure Control Unit
}

\begin{abstract}
Taiwo S. Amosun ${ }^{1}$ and Olusegun D. Samuel ${ }^{2}$
0000-0003-0595-763X, 0000-0002-6625-2820

${ }^{1}$ Department of Mechanical and Mechatronic Engineering, Federal University Otuoke,Bayelsa,

${ }^{2}$ Department of Mechanical Engineering, Federal University of Petroleum Resources, Effurun, Nigeria

\section{Abstract}

Tyre pressure plays a significant role in ensuring safe and economical driving. This research work was accomplished in two major steps. A novel tyre pressure control unit was developed using a mechatronic engineering approach of system integration for the control of car tyre inflation pressure. The control unit is designed to comprise an air compressor, microcontroller, pressure sensor and rotary valves. A software program waswritten and embedded in the microcontroller which counts the number of pulses in the pressure sensor. The paper also goes further toillustrate ordinary (non-survival), alinear regression model for the variations in energy and inflation time with inflation pressure. The results obtained showed that the values of energy and inflation time increased and varied for the tyre specimen considered. The developed statistical modelshelp to predict required energy and inflation time at different inflation pressures.
\end{abstract}

Keywords: Control; Regression; Software; Pressure; Mechatronic

\author{
Research Article \\ https://doi.org/10.30939/ijastech..927428
}

$\begin{array}{ll}\text { Received } & 25.04 .2021 \\ \text { Revised } & 15.07 .2021 \\ \text { Accepted } & 23.07 .2021\end{array}$

* Corresponding author

Taiwo Amosun

amosunts@fuotuoke.edu.ng

Address: Mechanical and Mechatronics Engineering Department, Faculty of Engineering, Federal University, Otuoke Nigeria

Tel: +2348038118476

\section{Introduction}

Regulating the tyre pressure constantly while in operation is very critical to its operation and performance. Over and un- derinflation of tyres either increase the wear rate of the centre of the tyre, causes the tyre to lose traction, reduce tyre foot- print, affect braking and vehicle performance and increase fuel consumption [1]. Generally, adjusting the accurate tyre pressure is essential for good handling, traction, and durability [2,3]. As expected, accurate tyre inflation pressure enables drivers to achieve comfort during driving coupled with the durability of the tyre. In spite of the numerous benefits aforementioned, there is a need to establish means of sustaining tyre inflation pressure. Recently, research studies show that a simple inflation system that is easy and inexpensive to produce would bring huge savings in fuel, pollution, and hu- man lives when implemented on a large scale [4]. Simango et al. (2017) reported that most road accidents attributed to tyre failure were due to insufficient air pressure in the tyres [5]. The need to monitor the pressure in these tyres is para- mount since they are the linkage between the vehicle and the ground and also facilitate vehicle movement. In a passenger car tyre; the recommended inflation pressure lies within the 2.4-3.5bar pressure range. Barber et al. (2004) also revealed that a decrease of 0.5 bar in the recommended tyre pressure may increase the tyre rolling resistance by $10 \%$, leading to an increase in fuel consumption by $2.5 \%$ [6]. A car that has tyres that are $20 \%$ underinflated has an increased rolling resistance of $20 \%$; reducing tyre lifetime by up to $50 \%$ and leading to increased fuel consumption by $6 \%$. Even then, many vehicles with underinflated tyres are observed to be on the road due to the unawareness of the fact that correct tyre inflation, within the design limits of loads and speed, can save tyre life up to $20 \%$ which is nine months of its life span. It can also save fuel from $4 \%$ to $10 \%$, increase braking efficiency up to $20 \%$, lightens the steering system and ease self-steer. The reported impacts of the tyre under inflation include approximately $5-12 \%$ degradation in tyre wear for an individual tyre which is 0.75 bar underinflated, and 0.5 $1.0 \%$ increase in fuel consumption (degradation in fuel economy) for a vehicle running with all tyres underinflated by 0.75 bar $[7,8$,$] .$ The outside temperature also has an impact on tyre pressure. During summer, the air in the tyre occupies more volume whereas, in winter, the air occupies less volume. Heat build-up in the tyre due to natural tyre flexing stabilizes at a safe temperature during its normal operation within its load range. Temperature above 394 oC 
results in the loss of tyre strength, the rubber-to- cord bond separates, and the air escapes, often as a blowout, and in some cases, they start to burn. The simplest method to reduce heat is to slow the vehicle speed, which decreases flexing per minute and provide more cooling time between flexing [9]. Tyre inflation pressures are recommended to have the best compromise for load-carrying capacity, vehicle handling, and tyre life. Greater fleet productivity and protection of fleet assets can be obtained through an effective tyre pressure management system. As of now, tyres are not manufactured in Nigeria. Most of the tyres used in the country are used tyres with few new ones. Kayisoglu et al (2014) indicated that the standard thickness of the used tyre threads will be reduced with continual use and un-monitored pressure, this tyre easily burst thereby posing a serious threat to human life. However, the majority of tyres of various specifications exist in Nigeria [10]. Table 1 depicts the average values of some tyre specifications in Nigeria.

Table 1. Types of tyre available in Nigeria [11]

\begin{tabular}{c|c}
\hline Maximum Load $(\mathrm{kg})$ & 692 \\
\hline Diameter $(\mathrm{mm})$ & 0.3 \\
\hline Maximum Pressure(bar) & 3,25 \\
\hline Section Width $(\mathrm{mm})$ & 201 \\
\hline
\end{tabular}

Not quite long, Krivtsov et al. [12] developed an empirical tool for tyre failure. The model was reported to assist in identifying the source of failure. Schjønning et al [13] also modelled the influence of tyre inflation pressure on the stress distribution interface. To the best authors' knowledge, the report on the effect of inflation tyre pressure on the energy and inflation time and its regression models is absent in the literature. Pelc (2007) has indicated that such models are relevant for adequate diagnosing tools to prevent untimely wear of tyre and futuristic planning. In spite of wide exploration of design and modelling of tyres, few reports exist on models to measure energy and inflation time of tyre pressure control system [14]. From the foregoing literature cited, there are almost no detailed reports on the development of models for tyre pressure control systems. Therefore, in order to eliminate the lapses in the knowledge of such reports in the literature, regression models to measure energy and inflation time was developed. The energy and inflation time correlations will go a long way for the researchers and designers for appropriate and systematic tyre control, improving fuel consumption, as well as ensuring safety and drivability.

\section{Materials and method}

Various components are required for the fabrication and assembly of a tyre pressure control unit. It consists of an air compressor, actuator, microcontroller, pressure sensors, indicator, display unit and relay. The control loop was divided into three parts; measurement by a sensor connected to the tyre, decision in a controller element, action through an output device (actuator). The monitoring system is an automated sys- tem that regulates and maintains the air pressure in the tyre at a preset pressure level. Figure1 presents the schematic of the tyre pressure control.

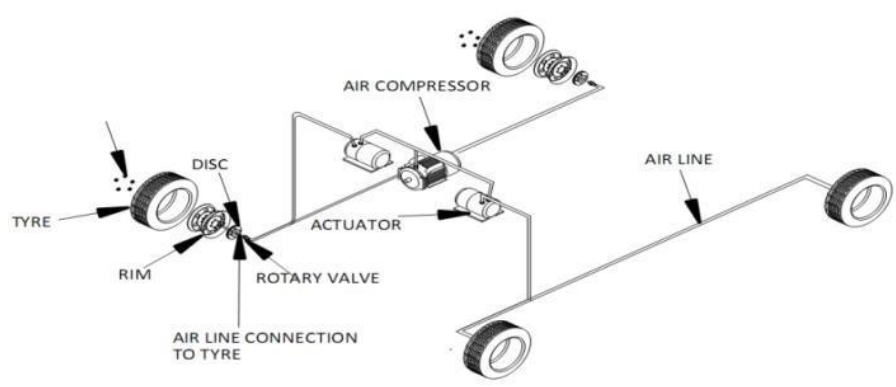

Fig. 1: Schematic diagram of the tyre pressure control unit.

\subsection{Design for the major components of the unit}

\subsubsection{Design of diaphragm tyre pressure sensor}

The sensor was designed and calibrated for 0 to 4.50 bar static pressure variations. The output voltage per volt of excitation for the sensor (B0) was designed with the aid of Eq. (1) and the detail discussed elsewhere [15].

$$
B_{0}=\frac{(0.82) P R_{d}^{2}\left(1-V^{2}\right)}{E t_{d}^{2}}
$$

$\mathrm{P}, \mathrm{Rd}, \mathrm{V}, \mathrm{E}$ and $\mathrm{td}$ are the maximum pressure (bar), radius of diaphragm (m), Poisson's ratio, Young modulus (N/m), and diaphragm thickness (m), respectively.

\subsubsection{Diaphragm deflection}

Sensor output is determined from the center deflection $\left(D_{c}\right)$ of the diaphragm as expressed in Eq. (2) and reported by Mohapatra [15]. For a perfect linearity condition, the deflection, $D_{c}<t d 4$ at the maximum pressure where $D_{c} \leq t_{d}$.

$$
D_{c}=\frac{3 P R_{d}^{4}\left(1-V^{2}\right)}{16 E t_{d}^{3}}
$$

\subsubsection{Air compressor}

The air compressor which is always on a standby mode is triggered to inflate the tyre by the microcontroller. The volume of pressurized air supplied by the compressor to inflate the tyres is calculated with Eq. (3), which is in line with the method adopted by Rashidi et al. [16]. The air supplied from the compressor is sopped when the maximum air pressure is attained as sensed by the pressure sensor.

$$
V_{p a}=V_{t a} \frac{M_{a x_{a p}}-M_{i n_{a p}}}{A_{p}}
$$

where Maxap, Maxap, $A p$ are the maximum air pressure of the tyres (bar), minimum air pressure of the tyre (bar) and at-mosphere pressure (bar) while $\mathrm{V}_{\text {pa }}$ and $\mathrm{V}_{\text {ta }}$ arethe re-quired pressurized air volume to inflating all the tyres $\left(\mathrm{m}_{3}\right)$ and total air volume in the tyre (m3), respectively. 


\subsubsection{Rotary valves}

The rotary valves inflate the tyres with the help of the solenoid valves attached to them. The valves which are connected to the centre of the external rim of the tyres move independently of the tyres.

\subsubsection{Design of microcontroller}

This design employed a programmable intelligence computer, PIC16f876a, which serves as the brain of the unit. It is an intelligent system that is capable of monitoring an event and taking a decision based on the data gathered. It monitors four pressure sensors attached to the micro inputs. The pressure sensor was made of spongy foam doped with resistor proper-ties. When the sensor is depressed the resistance of the probe decreases. A software program was written and embedded in the microcontroller which counts the number of pulses in the pressure sensor. The $4 \mathrm{mhz}$ crystals provide the operating speed for the microcontroller.

\subsubsection{Actuator}

The unit consists of four relays, the front left, front right, rear left and rear right. When the pressure sensors have not beenpressed the reading on LCD displays is minimal. As the air supplied to the tyre begins to saturate, the return pressure be-gins to act on the sensors. This pressure on the sensors causes the resistance of the input to the microcontroller to alter in accordance with the level of pressure experienced by the sensors. All sides of the input to the microcontroller have an equal priority that provided operating speed to the microcontroller. The side that experiences the level of pressure that was calibrated to be the ideal pressure for the tyre stops the air pumped into the tyre. On the other hand, any tyre that experiences a reduction in the air that is in it short of the programmable ideal level gets pumped till the ideal pressure level is attained. The opening and closing of the actuator are done by the opening and closing of the relay attached to both sides of the tyre.

\section{Development of the models for energy and inflation time}

This work used an existing database obtained from previous research on tyre inflation by the authors to develop the regression equations. The pressure control unit was designed to operate between the minimum pressure limit of $0.35 \mathrm{bar}$ and maxi-mum pressure limit of 3.50bar.During the experiment, the following parameters were recorded: nominal pressure of the tyre, change in inflation pressure of the tyre at every 0.35 bar. The electrical energy required to inflate was determined using $\mathrm{Eq}(4)$.

$$
W=I_{h} V_{t} / 360 \text { Joules }
$$

where Ih $=$ current $(\mathrm{Ah})=100 \mathrm{Ah}, \mathrm{V}=$ voltage $(\mathrm{v})=12 \mathrm{~V}, \mathrm{t}=$ inflation time.

The energy (W) and inflation time (ts ) vs. inflation pressure $(d p s)$ required to inflate R16 tyre size at zero nominal pressure were expressed by Eqs. (5) and (6), respectively.

$$
\begin{aligned}
& W=-\beta_{1} d_{p s}^{2}+\beta_{2} d_{p s}-\beta_{3} \\
& t_{s}=-\beta_{4} d_{p s}^{3}+\beta_{5} d_{p s}^{2}+\beta_{6} d_{p s}+\beta_{7}
\end{aligned}
$$

The $\mathrm{W}$ and $t_{s} \mathrm{vs.} d p s$ required to inflate $\mathrm{R} 15$ tyre size at zero nominal pressure were correlated with the Eqs. (7) and (8), respectively.

$$
\begin{aligned}
& W=\beta_{8} d_{p s}-\beta_{9} \\
& t_{s}=\beta_{10} d_{p s}+\beta_{11}
\end{aligned}
$$

The $\mathrm{W}$ and $t s$ as a $d p s$ required to inflate $\mathrm{R} 15$ tyre sizeat zero nominal pressure were correlated withEqs. (9) and (10), respectively.

$$
\begin{aligned}
& W=-\beta_{12} d_{p s}^{2}+\beta_{13} d_{p s}+\beta_{14} \\
& t_{s}=\beta_{15} d_{p s}^{2}+\beta_{16} d_{p s}+\beta_{17}
\end{aligned}
$$

\section{Results and discussion}

\subsection{Principal units of tyre pressure control unit}

Table 2 summarizes the designed parameters utilized for the tyre pressure control unit. In addition, the components were assembled according to functions.

Table 2. Principal units of the tyre pressure control unit

\begin{tabular}{|c|c|}
\hline Output Voltage (mv/v) & 2 \\
\hline Hose's Diameter (cm) & 0.3 \\
\hline $\begin{array}{c}\text { Total Pressurized air } \\
\text { vol.req.(bar) }\end{array}$ & 180 \\
\hline Power required (Watt) & 115.31 \\
\hline Compressor's Capacity (bar) & 20.7 \\
\hline
\end{tabular}

\subsection{Correlation developed for the energy and inflation time}

Figures (2) to (4) depict the correlations developed for the energy (Ws ) and inflation time (ts ) and presented in Table 3. As noticed in the curves, varying ranges of inflation pressure (dps) has a slight impact on the $W$ sand $t s$ of the fabricated tyre control unit. Variations in the $W s$ and $t s$ vs. dps for the control unit of R16 tyre is depicted in Figure 2. As observed, the $W s$ and $t s$ values of the unit increased and varied between 10 and $111 \mathrm{~J}$ and 30 and $233 \mathrm{~s}$ as the dps increased from 0.35 to $3.5 \mathrm{bar}$, respectively. The quadratic equation such as $(-4.3599 \mathrm{dps} 2+50.448 \mathrm{dps}-10.35)$ and polynomial equation $(-5.7539 \mathrm{dps} 3+28.59 \mathrm{dps} 2+31.313 \mathrm{dps}+20.6)$ are detected suitable for the changes of $W s$ and $t s$ vs. dps because of the high regression coefficient $\left(\mathrm{R}^{2}\right)$ of 0.9954 and 0.9908 , respectively. 
Table 3. Correlation between the energy and inflation time vs. inflation pressure

\begin{tabular}{|c|c|c|c|}
\hline Relation & Model Equations & $\begin{array}{c}\text { Tyre } \\
\text { Type }\end{array}$ & $\mathrm{R} 2$ \\
\hline $\begin{array}{c}\text { Energy- } \\
\text { Inflation } \\
\text { Pressure }\end{array}$ & $\mathrm{WS}=-4.3599 \mathrm{dPs} 3+50.448 \mathrm{dPs} 2-10.35$ & $\mathrm{R} 16$ & 0.9954 \\
\hline $\begin{array}{c}\text { Infla- } \\
\text { tion- } \\
\text { Time- } \\
\text { Inflation } \\
\text { Pressure }\end{array}$ & $t \mathrm{~S}=-5.7539 \mathrm{dPs} 3+28.59 \mathrm{dPs}+31.313 \mathrm{dps}$ & $\mathrm{R} 16$ & 0.9908 \\
\hline $\begin{array}{c}\text { Energy- } \\
\text { Inflation } \\
\text { Pressure }\end{array}$ & $\mathrm{WS}=40.156 \mathrm{dps}-0.2$ & $\mathrm{R} 15$ & 1 \\
\hline $\begin{array}{c}\text { Infla- } \\
\text { tion- } \\
\text { Time- } \\
\text { Inflation } \\
\text { Pressure }\end{array}$ & $t \mathrm{~S}=120.35 \mathrm{dps}-0.266$ & $\mathrm{R} 15$ & 1 \\
\hline $\begin{array}{c}\text { Energy- } \\
\text { Inflation } \\
\text { Pressure }\end{array}$ & $\mathrm{WS}=0.2783 \mathrm{dps} 2+27.708 \mathrm{dps}+0.95$ & $\mathrm{R} 13$ & 0.9996 \\
\hline $\begin{array}{c}\text { Infla- } \\
\text { tion- } \\
\text { Time- } \\
\text { Inflation } \\
\text { Pressure }\end{array}$ & $t \mathrm{~S}=0.525 \mathrm{dps} 2+84.002 \mathrm{dps}+2.6167$ & $\mathrm{R} 13$ & 0.9998 \\
\hline
\end{tabular}

In similar research work on tyre, Rashidi et al. [16] established a regression coefficient of 0.986 for three-model linear regression in their studies of prediction of bias-ply tyre de-flection based on contact area index, inflation pressure and vertical load.

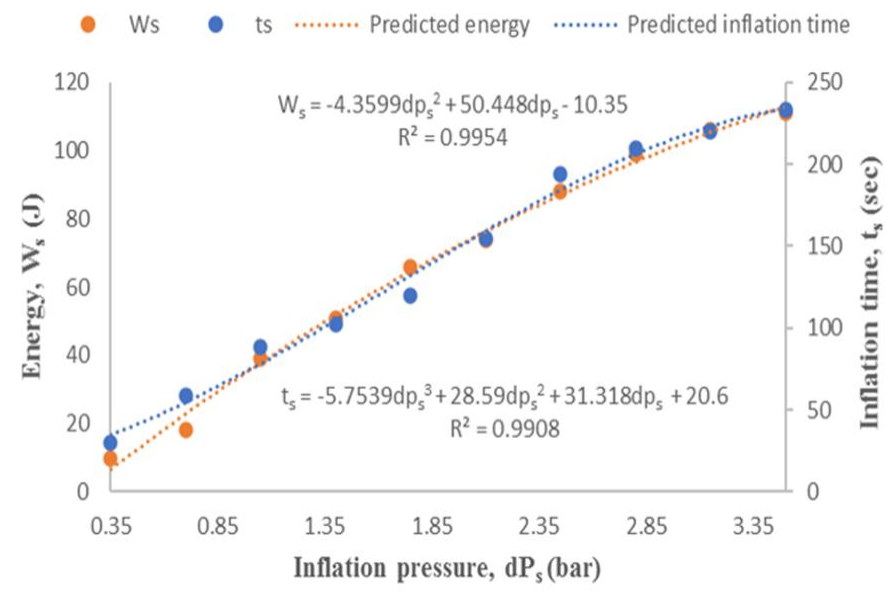

Fig. 2. Predicted inflation time and energy vs. Inflation pressure for

$$
\text { R13 tyre }
$$

Changes in the $W s$ and $t s$ vs. dps for the control unit ofthe R15 tyre are portrayed in Figure 3. As detected, the $W s$ and ts values of the unit increased and varied between 14 and $141 \mathrm{~J}$ and 42 and $423 \mathrm{~s}$ as the dpsincreased from 0.35 to $3.5 \mathrm{bar}$, respectively. The linear equations such as ( $120.35 \mathrm{dps}-0.2667)$ and (40.156dps $0.2)$ are detected suitable for the changes of $W s$ and $t s$ vs. dps because of R2 of 1.0 for the model.

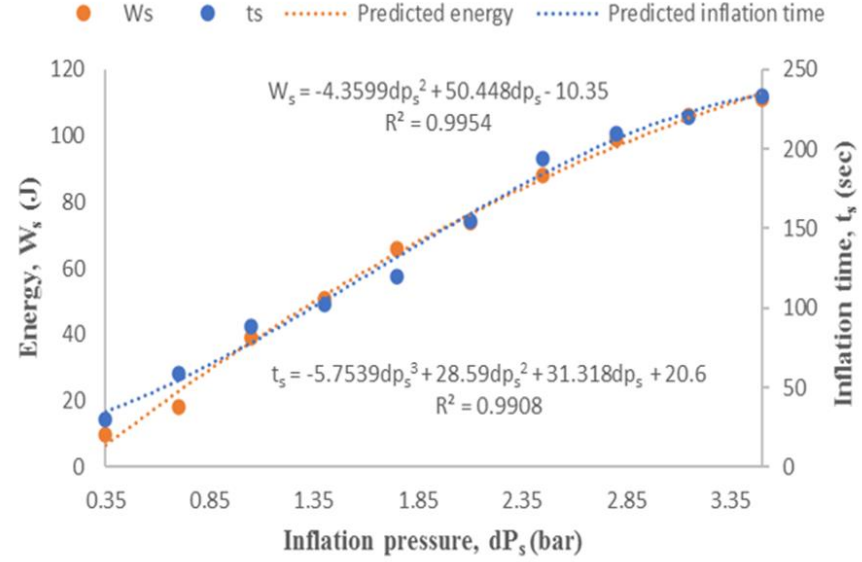

Fig. 3. Predicted inflation time and energy vs. Inflation pressure for R15 tyre

Variation in the $W s$ and $t s$ vs. dps for the control unit of R13tyreis shown in Figure 4. As shown, Ws and ts values of the unit increased and varied between 11 and $101 \mathrm{~J}$ and 33 and 302s as the dps increased from 0.35 to $3.5 \mathrm{bar}$, respectively. The quadratic equations such as $(0.2783 \mathrm{dps} 2+27.708 \mathrm{dps}+0.95)$ and $(0.5257 \mathrm{dps} 2+84.02 \mathrm{dps}+2.6167)$ are confirmed adequate for the changes of Ws and ts vs. dps because of high R2 of 0.996 and 0.9998 , respectively.

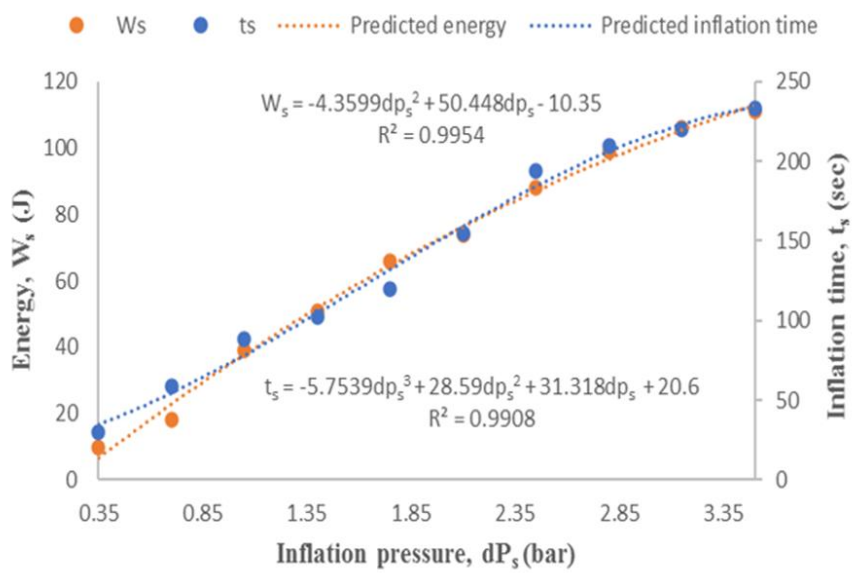

Fig. 4. Predicted inflation time and energy vs. Inflation pressure for R13 tyre

\section{Conclusions}

The study established the regression equation for predicting energy and inflation time for a fabricated tyre pressure control unit abetted with the least-square statistical regression. To acquire a robust study in the nearest future, (i) smart tyres equipped with sensors to monitors parameters such as tread wear, air pressure, temperature, and friction, (ii) uncertainty assessment of smart tyres, (iii) exploration of soft computing on multiple input-multi-responses, and (iv) tyre pressure con trol system technology using other modelling methods such as computer simulations and predictions can be further investigated. The following conclusions can be deduced 
from this study:

- Energy (Ws) and inflation time (ts) are correlated with ranges of inflation pressure (pressure limits of 0.35 and 3.50 bar) through the least regression meth- od. The linear equation, quadratic equation, and parabolic equation are suitable for the Ws at R15 R13, and R16 tyres. The linear equation, quadratic equation, and parabolic equation are suitable for the ts at R15, R13, and R16 tyres

- This can be very useful to the researchers and designers in the field of tyre pressure control systems. It should be noted that the system was not designed for sudden and violent opening or breaking of the tyre. The system was not also designed for used tyres. However, it is recommended that more work should be done on tyre pressure control system technology using other modeling methods such as computer simulations and predictions.

\section{Conflict of Interest Statement}

The authors declare that there is no conflict of interest in the study.

\section{CRediT Author Statement}

Taiwo Amosun: Experiment design, writing the article, Olusegun Samuel: Creation of regression equations, Solution of regression equations

\section{References}

[1] Kubba, A.E., Jiang, K.A. Comprehensive Study onTechnologiesof Tyre Monitoring System and Possible Energy Solutions.United States of America Open Access Sensors Journal, pp.12-19, 2011.

[2] Gillespie, T.D. Fundamental of Vehicle Dynamics. Pen-ysylvannia, PA, USA International Journal of Society of Au- tomative engineers, 2(2): 137-139, 1992.

[3] Mushiri, T., Allan, T., Mbohwa,C.Design of an automatic tyre pressure inflation system for small vehicles. Proceedings of the 2016 International Conference on Industrial Engineering and Operation Management, Detroit, Michigan, USA, September 23-25, 2016.

[4] Matusko, J., Petrovic, I., Pevic, N.Neural Network BasedTyre/Road. Friction Force Estimation. Journal of En- gineering Applications of Artificial intelligence, 3(21): 442- 456, 2008.

[5] Simango, D., Musaidzi, H., Rangi, B.P., Mlambo, P., Muvunzi, R. Design of a real time tyre pressure monitoring system. $11^{\text {th }}$ Zimbabwe International Research Symposium, Harare, 2017.

[6] Barber,T.E., Remer, S.Y.,Sandlass, G.S., Maki, A.Predicting Tyre HandlingPerformance Using Neural Network mod- els.SAE Technical Paper: 01-1574, 2004.

[7] Yang, X., Behrooz, M., Olatunbosun, O.A. A neutral networkapproach to predicting car tyre micro-scale and macro-scale behavior. Journal of intelligent learning system and applica- tions, 6:11-20, 2014.

[8] Ivanov, V., Shyrokau B., Augsburg K., Gramstat S.Advancement of vehicle dynamics control with monitoring the tyre rolling environment.SAE International Journal ofPassenger Cars-Mechanical System,3(1):198-216, $2010 b$.
[9] Gosh, P. Optimization of TyreDesign Parameters through Finite Element Analysis and Correlation with Performance. SAETechnical Paper, 26043, 2007.

[10]Kayisoglu, B.,Engin, Y.,Dalmis, I.S.,Akdemir, B., Bayhan, Y.,Kullukcu, A. Developing an Automatic Tyre Pressure Control System To Improve the Tractive Efficiency of Trac- tors. Journal of Agricultural Machinery Science, 10 (3): 253-259, 2014.

[11]Amosun, S.T.Development of a tyre pressure control unit. Unpublished Ph.D thesis, Abeokuta, Nigeria, 2016.

[12]Krivtsov,V.V.,Tananko,D.E., Davis, T.P. Regression Approach to Tyre Reliability Analysis. Journal ofReliability Engineering and System Safety,78 (3): 267-273, 2002.

[13]Schjønning, P.,Lamandé, M., Tøgersen, F.A., Arvidsson, J., Keller, T. Modelling Effects of Tyre Inflation Pressure on theStress Distribution Near the Soil-Tyre Interface. Journal of Biosystems Engineering,99 (1):119-133, 2008.

[14]Pelc, J. Towards realistic simulation of deformationand stresses inpneumatictyres. Journal of Applied Mathematical Modeling, 31:530-540, 2007.

[15]Mohapatra, A.G.Design and Implementation of Dia- phragmTyre Pressure Sensor in a Direct Tyre Pressure Monitoring System for Automotive Safety Application International Journal of Engineering Science and Technology;8(3): 6514-6524, 2011.

[16]Rashidi,M., Azadeh, S., Fatehirad, P., Emadi, S.M., Lofti-Aski, A. Prediction of Bias-Ply Tyre Deflection Based on Contact Area Index, Inflation Pressure and Vertical Load Using Linear Regression Model. Journal of World Applied Science, 911-918, 2013. 